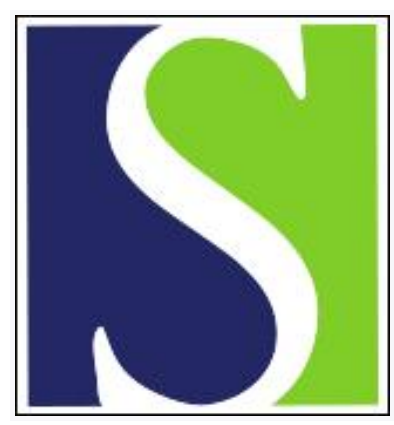

Scand J Work Environ Health 1989;15(5):319-322

https://doi.org/10.5271/sjweh.1844

Issue date: Oct 1989

Nonmalignant respiratory disease among hematite mine workers in China.

by Chen SY, Hayes RB, Wang JM, Liang SR, Blair A

Affiliation: Institute of Occupational Medicine, Chinese Academy of Preventive Medicine, Beijing, People's Republic of China.

This article in PubMed: www.ncbi.nlm.nih.gov/pubmed/2799317

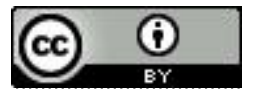




\title{
Nonmalignant respiratory disease among hematite mine workers in China
}

\author{
by Shu-yang Chen, MD, ${ }^{1}$ Richard B Hayes, PhD, ${ }^{2}$, Jian-min Wang, ${ }^{3}$ SR Liang, ${ }^{1}$ \\ Aaron Blair, $\mathrm{PhD}^{2}$
}

\begin{abstract}
CHEN S, HAYES RB, WANG J, LIANG SR, BLAIR A. Nonmalignant respiratory disease among hematite mine workers in China. Scand J Work Environ Health 1989;15:319-322. The mortality risk of nonmalignant respiratory disease among hematite workers in the Longyan and Taochong mines of China was investigated in a retrospective cohort study covering the period 1970-1982. The cohort was limited to men and consisted of 5406 underground miners, of whom $1335(25 \%)$ were diagnosed as having silicosis. Among those with silicosis, $560(42 \%)$ were diagnosed as having silicotuberculosis. Among the 490 underground miners who died, $278(57 \%)$ died of nonmalignant respiratory disease. The relative risk for death due to nonmalignant respiratory disease for stage III silicotics compared to nonsilicotics was almost 100-fold. High dust exposure was associated with a statistically significant increase in risk of death due to nonmalignant respiratory disease (relative risk 5.3). The relative risk associated with jobs with high dust exposure before the introduction of industrial hygiene controls was 7.7, and the corresponding value for after their introduction was 2.3 . There is a need for continued close monitoring of industrial hygiene in these mines.
\end{abstract}

Key terms: epidemiology, mortality, risk factors, silicosis.

The impact of occupational exposure to dust on mortality among miners can be great, particularly for persons with silicosis and silicotuberculosis. Mechanical ventilation and wet drilling are two techniques that reduce dust levels. In China these techniques were introduced to the Longyan mine in 1955 and to the Taochong mine in 1963, the concentration of total airborne dust, measured gravimetrically, being reduced from several hundred milligrams per cubic meter to less than $10 \mathrm{mg} / \mathrm{m}^{3}$ on the average. Monitoring data from the Longyan mine from 1971 to 1979 showed average dust levels of 3.8 (range $1.8-9.2$ ) $\mathrm{mg} / \mathrm{m}^{3}$ $(\mathrm{N}=4655)$ for mining and drilling operations and 2.7 (range $1.2-3.0) \mathrm{mg} / \mathrm{m}^{3}(\mathrm{~N}=167)$ for loading machine operations. Because pneumoconiosis is a statutory occupational disease in China, periodic health examinations including a physical examination and chest radiography have been offered since the early 1960 s on an annual or semiannual basis to workers with occupational exposure to hazardous dusts.

The association between exposure to silica and silicosis has been clearly established. Silicosis is the most common serious occupational disease in China (1), millions of workers being estimated as exposed to silica. In this paper we describe the extent of mortality due to nonmalignant respiratory disease in two Chinese

1 Institute of Occupational Medicine, Chinese Academy of Preventive Medicine, Beijing, People's Republic of China.

2 Epidemiology and Biostatistics Program, US National Cancer Institute, Rockville, Maryland, United States.

3 Chinese Academy of Preventive Medicine, Beijing, People's Repubiic of China.

Reprint requests to: Dr RB Hayes, National Cancer institute, Executive Plaza North, Room 418, 6130 Executive Boulevard, Rockville, MD 20892, USA. hematite mines and assess risk factors for this disease. Specifically, the relationships of mortality due to nonmalignant respiratory disease with employment in dustrelated jobs and with the introduction of ventilation and wet drilling are examined.

\section{Subjects and methods}

The personnel files of the two mining companies were reviewed, and 8641 men were identified who were employed on 1 January 1970 . Their vital status as of 31 December 1982 was determined by individual tracing interviews and, when necessary, by a postal questionnaire sent to the subjects or their next-of-kin. Vital status was ascertained for $8534(99 \%)$ of the subjects. The 107 people lost to follow-up were excluded from the study.

Using a questionnaire, we obtained information on occupational history at the mines from the subjects or, if deceased, from their next-of-kin. We excluded 3128 $(36 \%)$ workers as ineligible for the study. The subjects excluded were those who had been employed at the mines less than one year prior to 1 January 1970 , those who had worked in taconite $\left(\mathrm{Fe}_{3} \mathrm{O}_{4}\right)$ mining, and those who worked exclusively aboveground. By these criteria, 5406 subjects (Longyan mine 4824, Taochong mine 582) were included in the study. They were grouped by job title into workers with low, medium, and high exposure to dust according to the job held for the longest period of time underground. The workers with low exposure $(\mathrm{N}=772)$ had jobs as, eg, safety workers, ventilation workers, and storekeepers. The workers with medium exposure $(\mathrm{N}=1197)$ had jobs such as loading machine operator, conveyor oper- 
ator, electric train operator, and track maintenance. The heavily exposed workers $(\mathrm{N}=3437)$ were all directly involved in drilling and mining at the face of the mine.

According to criteria for diagnosis established in China in $1963(1), 1335(24.7 \%)$ of the subjects had been diagnosed as having silicosis by review panels of physicians specialized in occupational medicine and radiology. Radiographic examination of the chest, the posterior-anterior view being the standard position, is the basic approach used in the diagnosis and classification of pneumoconioses. The pneumoconioses are classified in four stages from class 0 , showing no or only minor radiographic manifestations of pneumoconiosis, to class III, which includes large opacities of not less than $2 \times 1 \mathrm{~cm}$. The intermediate classes I and II show smaller opacities and are distinguished from each other by the profusion and extent of the radiographic abnormalities.

For the deceased workers, cause of death was generally obtained from the records of the pension department. Causes of death were recorded according to the ninth revision of the International Classification of Diseases (ICD) (2). Further details of the study design have been provided in a recent publication primarily concerned with cancer risk (3).

For the present statistical analysis of nonmalignant respiratory disease, person-years were accumulated from the study entry date (1 January 1970) until the date of death or until 31 December 1982, whichever occurred first. Crude and directly standardized mortality rates have been presented. For the direct standardization procedure (4), the age distribution at the entry of the total population into the study was used as the standard. In the assessment of the effects of multiple variables on the risk of death, regression analyses based on a Poisson model (5) were carried out with generalized linear modeling (6). In the regression analysis, the importance of the level of each factor can be assessed by comparing the standard error (SE) to the regression coefficient (B). The relative risk (RR) is derived as the antilog of the regression coefficient (B), and the $95 \%$ confidence interval $(95 \% \mathrm{CI})$ as the antilog of $\mathrm{B} \pm 1.96 \mathrm{SE}$

Table 1. The mine workers by age in 1970 and stage of silicosis.

\begin{tabular}{|c|c|c|c|c|c|c|}
\hline \multirow{3}{*}{$\begin{array}{l}\text { Age } \\
\text { (years) }\end{array}$} & \multirow{3}{*}{$\begin{array}{l}\text { Number of } \\
\text { subjects }\end{array}$} & \multicolumn{5}{|c|}{ Subjects with silicosis ${ }^{a}$} \\
\hline & & \multirow{2}{*}{ Number } & \multicolumn{4}{|c|}{ Stage $(\%)$} \\
\hline & & & 1 & 11 & III & Total \\
\hline $\begin{array}{l}\leq 19 \\
20-29 \\
30-39 \\
40-49 \\
50-59 \\
60-69 \\
\geqslant 70\end{array}$ & $\begin{array}{r}3 \\
656 \\
2617 \\
1803 \\
275 \\
46 \\
6\end{array}$ & $\begin{array}{r}- \\
6 \\
436 \\
729 \\
138 \\
23 \\
3\end{array}$ & $\begin{array}{c}- \\
1 \\
9 \\
17 \\
18 \\
17 \\
17\end{array}$ & $\begin{array}{l}-\overline{7} \\
\overline{7} \\
20 \\
25 \\
28 \\
33\end{array}$ & $\begin{array}{l}- \\
\overline{1} \\
3 \\
7 \\
4 \\
-\end{array}$ & $\begin{array}{r}- \\
17 \\
40 \\
50 \\
50 \\
50\end{array}$ \\
\hline Total & 5406 & 1335 & 11 & 11 & 2 & 25 \\
\hline
\end{tabular}

a According to reference 1 .

\section{Results}

The 5406 subjects provided 67733 person-years of follow-up. The distribution by age in 1970 and by silicosis status is shown in table 1 . About $25 \%(\mathrm{~N}=1335)$ of these underground mine workers had silicosis $(25 \%$ in the Longyan mine and $24 \%$ in the Taochong mine). Of the subjects over 50 years of age in $1970,50 \%$ had been diagnosed as having silicosis, more than $30 \%$ having been diagnosed with stage II or stage III. Of the 1335 subjects with silicosis, 560 (42\%) had silicotuberculosis, while, of the 4071 nonsilicotics, only $7(0.2 \%)$ had lung tuberculosis.

Of the 5406 subjects, 2110 were employed before the introduction of wet drilling and ventilation controls, and 3296 were initially employed after the introduction of these control methods. Of those employed before the introduction of the controls, $1066(51 \%)$ had been diagnosed as silicotics, while only $269(8 \%)$ of those initially employed after the introduction of the controls had been diagnosed as silicotics.

As of 31 December 1982, $4916(91 \%)$ of the subjects were alive and $490(9 \%)$ were deceased. Of the deceased, $278(57 \%)$ had died of nonmalignant respiratory disease (ICD $011-012,416,460-519) ; 98$ $(20 \%)$ of malignant neoplasms, including $29(6 \%)$ of lung cancer; $34(7 \%)$ of circulatory causes, excluding chronic pulmonary heart disease (ICD 416); and $80(16 \%)$ of other causes. A total of 372 deaths occurred among the subjects employed before the introduction of mechanical ventilation and wet drilling, of which $65 \%$ were due to nonmalignant respiratory disease; while, among those initially employed after the introduction of industrial hygiene controls, there were 118 deaths, of which $30 \%$ were due to nonmalignant respiratory disease. For the silicotics, $75.8 \%$ of the deaths were due to nonmalignant diseases of the respiratory system, while for nonsilicotics $15.5 \%$ of the deaths were attributed to this cause.

Mortality due to all causes and due to nonmalignant respiratory disease is shown by stage of silicosis in table 2 . Silicosis proved to be a strong predictor of mortality. The age-standardized mortality rate for all causes was 574.6/10 000 person-years among the stage III silicotics and was only $34.1 / 10000$ person-years among the nonsilicotics. The difference in relative risk for nonmalignant respiratory disease in these two groups was almost 100 -fold.

Poisson regression analysis was used to examine the influence of multiple factors on mortality due to nonmalignant respiratory disease in this cohort. The following independent variables were entered into the regression analyses: age in $1970(<30,30-39,40-49$, $50-59$, $\geq 60$ years), job-exposure category (low, medium, high), ventilation (before and after); and time period of follow-up (1970-1974, 1975-1979, 1980-1982). The death rate due to nonmalignant respiratory disease in a particular stratum of the independent variables was modeled as a function of the 
Table 2. Crude ${ }^{\mathrm{a}}$ and directly standardized ${ }^{\mathrm{b}}$ rates for selected causes of death by stage of silicosis at the two hematite mines in $1970-1982$. ( $N=$ number of deaths)

\begin{tabular}{|c|c|c|c|c|c|c|c|c|c|c|c|c|}
\hline \multirow{3}{*}{ Cause of death } & \multicolumn{12}{|c|}{ Stage of silicosis ${ }^{c}$} \\
\hline & \multicolumn{3}{|c|}{ Stage $0^{d}$} & \multicolumn{3}{|c|}{ Stage le } & \multicolumn{3}{|c|}{ Stage $\mathrm{II}^{\dagger}$} & \multicolumn{3}{|c|}{ Stage IIfg } \\
\hline & $N$ & $\begin{array}{c}\text { Crude } \\
\text { rate }\end{array}$ & $\begin{array}{l}\text { Standard- } \\
\text { ized } \\
\text { rate }\end{array}$ & $\mathrm{N}$ & $\begin{array}{l}\text { Crude } \\
\text { rate }\end{array}$ & $\begin{array}{l}\text { Standard- } \\
\text { ized } \\
\text { rate }\end{array}$ & $\mathrm{N}$ & $\begin{array}{l}\text { Crude } \\
\text { rate }\end{array}$ & $\begin{array}{l}\text { Standard- } \\
\text { ized } \\
\text { rate }\end{array}$ & $N$ & $\begin{array}{l}\text { Crude } \\
\text { rate }\end{array}$ & $\begin{array}{l}\text { Standard- } \\
\text { ized } \\
\text { rate }\end{array}$ \\
\hline All causes & 155 & 29.6 & 34.1 & 100 & 133.7 & 115.5 & 170 & 240.3 & 178.3 & 65 & 656.8 & 574.6 \\
\hline $\begin{array}{l}\text { Nonmalignant } \\
\text { respiratory } \\
\text { diseaseh }^{\mathrm{h}}\end{array}$ & 24 & 4.6 & 5.8 & 65 & 86.9 & 63.0 & 127 & 179.5 & 133.9 & 62 & 626.5 & 559.0 \\
\hline $\begin{array}{l}\text { Silicosis and } \\
\text { silicotuberculosisi }\end{array}$ & - & $\cdots$ & $\cdots$ & 57 & 74.9 & 13.6 & 117 & 165.4 & 123.1 & 52 & 525.5 & 432.0 \\
\hline $\begin{array}{l}\text { Crude rate }\left(1 / 10^{4}\right) \text {. } \\
\text { b Direct standardiza } \\
\text { Based on the Min } \\
\text { d Number of worke } \\
\text { \& Number of worke } \\
\text { I Number of worke } \\
\text { g Number of worke } \\
\text { " Disease of the res } \\
416 \text {, and pulmon } \\
\text { Silicosis (ICD } 502\end{array}$ & $\begin{array}{l}\text { es }(1 / 1 \\
\text { Public } \\
\text { persor } \\
\text { person- } \\
\text { person- } \\
\text { jerson- } \\
\text { syster } \\
\text { other } r \\
\text { licosis }\end{array}$ & $\begin{array}{l}\text { 4) with th } \\
\text { Health's } \\
\text { years } 52 \\
\text { ears } 747 \\
\text { ears } 707 \\
\text { ears } 989 \\
\text { lInterna } \\
\text { spiratory } \\
\text { with lung }\end{array}$ & $\begin{array}{l}\text { he total num } \\
\text { medical reg } \\
287.8 \text {. } \\
8 . \\
4 . \\
.7 . \\
\text { tional Class } \\
\text { tuberculos } \\
\text { tuberculos }\end{array}$ & $\begin{array}{l}\text { ation } \\
\text { ICD } 0 \\
\text { CD } 01\end{array}$ & $\begin{array}{l}\text { Disease } \\
\text {-012). }\end{array}$ & $\begin{array}{l}\text { d mine wor } \\
\text { kers expose } \\
\text { es, ninth rev }\end{array}$ & as & $\begin{array}{l}\text { standa } \\
\text { dust. }\end{array}$ & 9], chronic & 10 & heart di & sease (ICD \\
\hline
\end{tabular}

independent variables, as described by Breslow \& Day (5). The relative risk for death due to nonmalignant respiratory disease is shown in table 3 for each of the variables after adjustment for the other variables in the model. Age in 1970 and time period of follow-up were strong predictors of nonmalignant respiratory disease mortality. For the job categories, only high exposure jobs were associated with an increase in risk (RR 5.3). Employment beginning before the introduction of ventilation was associated with a sixfold excess risk in comparison with employment beginning after the introduction of ventilation.

Analyses were carried out separately for those initially employed before and after the introduction of ventilation. For those employed before, the relative risk for nonmalignant respiratory disease associated with high-exposure jobs was 7.7 (95\% CI 3.2-18.6). For those initially employed after the introduction of ventilation, the associated relative risk was $2.3(95 \% \mathrm{CI}$ $0.8-6.7)$.

\section{Discussion}

Dust-related morbidity and mortality is a major health problem in some industries. Among underground gold mine workers, Brown et al (7) found that at least twothirds of the individuals who died from nonmalignant respiratory disease had a confirmed diagnosis of silicosis. Schüber \& Rütner (8) reported that $40 \%$ of the deaths of dust-exposed workers were of respiratory origin, including deaths due to bronchitis and emphysema, and Zambon et al (9) found that $50 \%$ of all deaths among dust-exposed workers from Italy were from diseases of the respiratory system and silicotuberculosis. Jorgenson (10) has indicated that workers with progressive silicosis are more likely to have tuberculosis also than are those with nonprogressive silicosis.
Table 3. Regression coefficients and associate relative risks for nonmalignant respiratory disease ${ }^{a}$ in Chinese hematite miners, $1970-1982$.

\begin{tabular}{lcccc}
\hline Factor & $\begin{array}{c}\text { Regression } \\
\text { coefficient }\end{array}$ & $\begin{array}{c}\text { Standard } \\
\text { error }\end{array}$ & $\begin{array}{c}\text { Relative } \\
\text { risk }\end{array}$ & $\begin{array}{c}95 \% \\
\text { confidence } \\
\text { interval }\end{array}$ \\
\hline Age (years) & & & & \\
$\quad 30$ & &. & 1.0 &. \\
$30-39$ & 2.30 & 1.00 & 10.0 & $1.4-70.8$ \\
$40-49$ & 3.13 & 1.01 & 22.9 & $3.2-165.6$ \\
$50-59$ & 4.00 & 1.02 & 54.6 & $7.4-403.1$ \\
$\geq 60$ & 4.21 & 1.06 & 67.4 & $8.4-537.9$ \\
Time period & & & & \\
1970-1974 & &. & 1.0 &. \\
1975-1979 & 0.47 & 0.15 & 1.6 & $1.2-2.1$ \\
1980-1982 & 0.77 & 0.16 & 2.2 & $1.6-2.9$ \\
Dust exposure & & & & \\
Low &.- &. & 1.0 & \\
Medium & -0.14 & 0.44 & 0.9 & $0.4-2.1$ \\
High & 1.66 & 0.34 & 5.3 & $2.7-10.2$ \\
Ventilation & & & & \\
After &. &. & 1.0 &. \\
$\quad$ Before & 1.80 & 0.19 & 6.0 & $4.2-8.8$ \\
Constant term & -11.16 & 1.05 &. &. \\
\hline
\end{tabular}

a Including diseases of the respiratory system (International Classification of Diseases, ninth revision (ICD) 460-519), chronic pulmonary heart disease (ICD 416), and pulmonary and other respiratory tuberculosis (ICD 011-012).

Silicosis morbidity was of major importance in the two Chinese mines examined in the present study, over $50 \%$ of the subjects employed before the introduction of hygiene controls having this disease. Furthermore, tuberculosis was strongly associated with silicosis. Workers in these mines were also at a greatly increased risk of mortality due to nonmalignant respiratory disease, which accounted for more than $50 \%$ of all deaths. In a Poisson regression analysis, accounting for age and time period of follow-up, strong independent associations appeared for the introduction of hygiene controls and for level of dust exposure with nonmalignant respiratory disease mortality. The higher risk among the workers initially em- 
ployed before the introduction of mechanical ventilation and wet drilling (RR 6.0) cannot be attributed simply to a longer duration of exposure. Workers employed before the introduction of hygiene controls were exposed, on the average, for 14 years to dust, while those initially employed after the introduction of hygiene controls were exposed an average of 16 years. In fact, many of the early workers were moved to unexposed jobs when symptoms of silicosis developed. The level of exposure to dust was strongly associated with nonmalignant respiratory disease mortality. Even among those initially employed after the introduction of the industrial hygiene measures, the risk was greater than twofold in jobs with high dust exposure. Although this later finding was statistically nonsignificant, it indicates the need for the close monitoring of industrial hygiene in these mines.

The results of this study were consistent with previous findings of high mortality due to nonmalignant respiratory disease among miners. The independent risk estimates were provided by job exposure category and by time period of employment respective to the introduction of industrial hygiene controls. The highest risks were associated with the dustiest jobs. Risk for silicosis and for death due to nonmalignant respiratory disease was considerably lower among the workers initially employed since the introduction of the industrial hygiene controls of mechanical ventilation and wet drilling.

\section{References}

1. The Ministry of Public Health, People's Republic of China. Medical regulations for workers exposed to silica dust. Beijing: The People's Medical Publishing House, 1963.

2. World Health Organization. International classification of disease; 1975 revision. Geneva: World Health Organization, 1977.

3. Chen SY, Hayes RB, Liang SR, Li QG, Stewart PA, Blair A. The mortality experience of hematite mine workers in China. Br J Ind Med (in press).

4. Rothman KJ, Boice JD Jr. Epidemiologic analysis with a programmable calculator. Boston, MA: Epidemiology Resources, Inc, 1982.

5. Breslow NE, Day, NE. Statistical methods in cancer research; vol 2 (The design and analysis of cohort studies). Lyon: International Agency for Research on Cancer, 1987. (IARC scientific publications, no 82.)

6. Healy MJR. GLIM: an introduction. Oxford: Oxford University Press, 1988.

7. Brown DP, Kaplan SD, Zumawalde RD, et al. Retrospective cohort mortality study of underground gold mine workers: silica, silicosis and cancer controversy in occupational medicine. Cancer Res Monogr 1986;2: $335-49$.

8. Schüber G, Rütner JR. Silicosis and lung cancer in Switzerland: silica, silicosis and cancer controversy in occupational medicine. Cancer Res Monogr 1986;2:357-66.

9. Zambon P, Simonato L, Mastrangelo G, Winkelmann R, Saia B, Crepet M. Mortality of workers compensated for silicosis during the period 1959-1963 in the Veneto region of Italy. Scand J Work Environ Health 1987; 13:118-23.

10. Jorgenson HS. Silicosis in the iron-ore mine in Kiruna, Sweden and the future need for silicosis control. Int Arch Occup Environ Health 1986;58:251-87.

Received for publication: 3 March 1989 